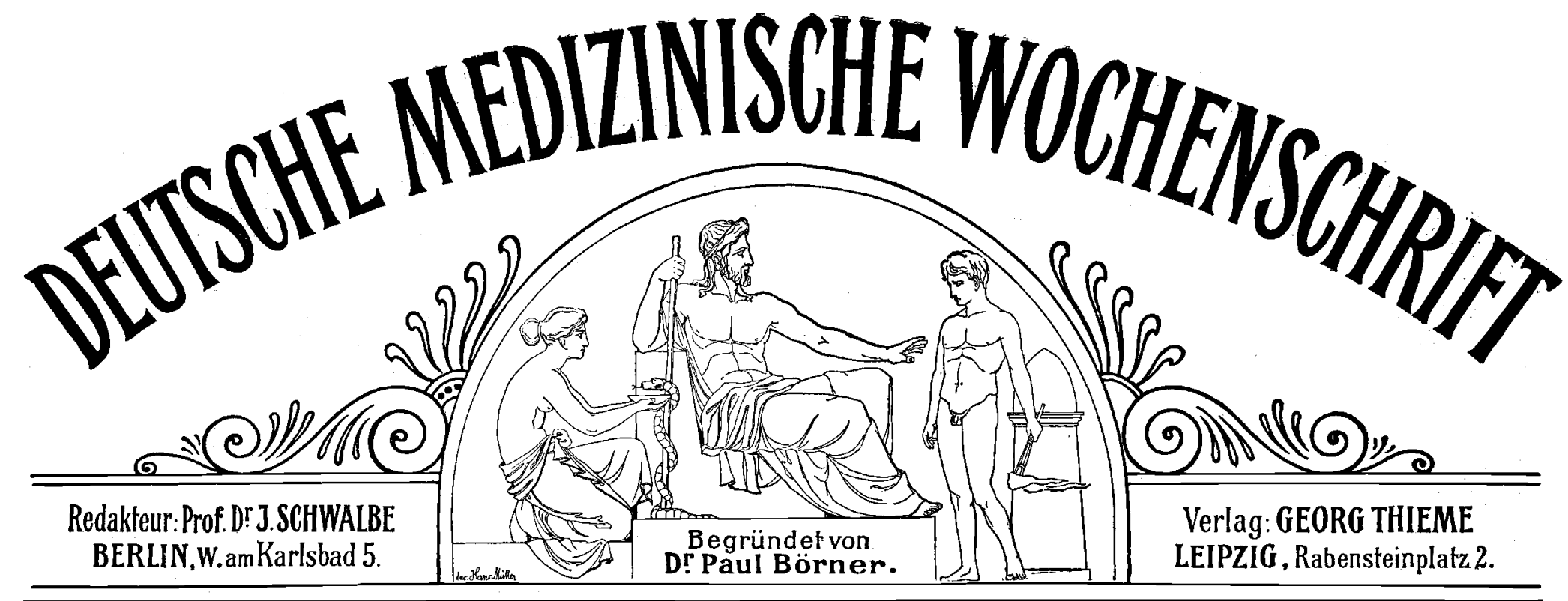

No. 46.

\section{Ueber Immunisierung von Rindern gegen Tuberculose (Perlsucht) und über Tuberculose- Serumversuche.}

Von Dr. Friedrich Franz Friedmann in Berlin.

In dieser Wochenschrift (1903, No. 50, und 1904, No. 5) habe ich mitgeteilt, daß die von mir aufgefundenen Schildkrötentuberkelbacillen (Schkr.-T.-B.) vollkommen ungefährlich für Warmblüter sind und daß es mittels derselben gelingt, dem tuberculoseempfänglichsten Säugetier, dem Meerschwein, einen hochgradigen Immunitätsschutz gegenüber einer späteren Infektion mit virulenten Tuberkelbacillen zu verleihen. Die bezüglichen zahlreichen Protokolle gelungener Meerschweinimmunisierungen werden demnächst publiziert werden. Es war sodann in der oben erwähnten Mitteilung die Vermutung ausgesprochen worden, dab auch Rinder nach meiner Methode gegen Perlsucht geschützt werden können. Diese Vermutung hat sich als richtig erwiesen.

Als Beweis für die Unschädlichkeit der Methode möge die Tatsache angeführt werden, daß eine größere Zahl von Rindern und Kälbern - übrigens auch anderen großen Haustieren außerordentlich große Mengen meiner Kultur intravenös ohne irgendwelche auf die Injektion zurückzuführende Schädigung und ohne bei der lange Zeit darauf stattgehabten Sektion irgendwelche Herde zu zeigen, vertragen haben.

Beispiel: Kalb I erhielt im Februar 0,3 g Schkr.-T.-B., im Mai $1,0 \mathrm{~g}$ Schkr.-T.-B., im Juni 2,0 g Schkr.-T.-B. intravenös. Es wurde am 19. September geschlachtet: Lungen vollkommen intakt ohne ein Knötchen; auch alle Drüsen vollkommen gesund, nicht einmal vergrößert. Leber, Milz glatt.

Ein zweites, in ähnlicher Weise und gleichzeitig in Behandlung genommenes Kalb wird zurzeit $\mathrm{zu}$ anderen Zwecken am Leben gehalten und ist bei bestem Wohlbefinden.

Was nun die wichtigste Frage anbetrifft: Bilden die Schkr.T.-B., wenn in geeigneter Form in den Rinderkörper eingeführt, in diesem spezifische Schutzstoffe, dergestalt, daß sie gesunde Rinder bei nachfolgender Infektion mit Perlsuchtbacillen vor einer allgemeinen Erkrankung bewahren, bei bereits erkrankten eine Heilung oder jedenfalls günstige Beeinflussung des tuberculösen Prozesses zu bewirken imstande sind? - so seien hier die Protokolle der bisher in den Höchster Farbwerken infizierten Rinder angeführt.

Rind V erhielt (abgesehen von einer sehr geringen und kaum in Betracht kommenden Injektion im November) am 23. Februar 1904 eine einmalige intravenöse Einspritzung mit Schkr.-T.-B.; es wurde am 9. Mai mit einer hochvirulenten Perlsuchtkultur intravenös infiziert. In der Folgezeit zeigte es, abgesehen von einem längere Zeit anhaltenden Fieber, keine besonderen Erscheinungen, nahm ständig an Gewicht zu (vor der Immunisierung $420 \mathrm{~kg}$, kurz vor der Infektion $480 \mathrm{~kg}$, zur Zeit der Tötung $535 \mathrm{~kg}$ ) und zeigte insbesondere zu keiner Zeit Husten oder Aurf $2,0 \mathrm{ccm} \mathrm{Koch} \mathrm{sches} \mathrm{Tuberculin} \mathrm{subcutan.} \mathrm{Es} \mathrm{zeigte} \mathrm{hierauf} \mathrm{zwar} \mathrm{eine}$ Reaktion, die aber nach zwölf Stunden schon wieder vollkommen abgeklungen war und der Normaltemperatur Platz gemacht hatte. Es war ferner auffallend, daß das Rind auch während der kurzen Reactionsperiode munter war, aufrecht stand und fraß. Am 17. August wurde das Rind geschlachtet: es fanden sich in den Lungen harte Knötchen, die aber nach Ausweis der mikroskopischen Untersuchung und der Meerschweinübertragung harmlose, durch Schkr.-T.-B. hervorgerufene Gebilde waren (die gleichen Knötchen zeigten auch einige nur mit Schkr.-T.-B. behandelte Rinder, die nicht inficiert worden waren). ${ }^{1}$ )

Irgendwelche als echte Tuberkelknötchen anzusprechende Herde fanden sich in den Lungen trotz genauester Untersuchung nicht, und die mit Lungenstïckchen geimpften Meerschweine erwiesen sich, nach acht Wochen getötet, als gesund. Die von den Lungen abhängigen Bronchialdrüsen des Rindes waren käsig-eitrig erweicht, aber von knorpelharten, bis $1 \mathrm{~cm}$ dicken Bindegewebskapseln umgeben. Dieser Befund zeigt, daß es sich um einen lokalen, in Ausheilung begriffenen Prozeß gehandelt hat.

Außerdem ist diese regionäre Drüsenerkrankung (bei Injektion in die Venen stellen die Drüsen am Lungenhilus die regionären Drüsen dar). sobald die Organe selbst frei sind, ohne spezifische pathognomische Bedeutung und von $\mathrm{K}$ och und Schütz wiederholt bei Schafen und Schweinen, die nur mit menschlichen Tuberkelbacillen behandelt wurden, beobachtet, ohne daß die Autoren hieraus eine Pathogenität der menschlichen Tuberkelbacillen für diese Spezies folgern. Aehnliche Beobachtungen machte Kossel mit verschiedenen menschlichen Tuberkelstämmen, die bei Rindern ebenfalls nur regionäre Drüsenaffektion, aber keine fortschreitende Tuberculose zu erzeugen imstande waren.

Alle übrigen Körperdrüsen und alle inneren Organe des Rindes V waren normal. Insbesondere wurde die Leber (vergleiche unten Kontrollrind) auf zahllosen Längs- und Querschnitten untersucht: es fand sich aber in ihr nicht ein einziges auch nur verdächtiges Fleckchen und die mit Leberstückchen geimpften Meerschweine blieben vollkommen gesund.

Kontrollrind VIII wurde ebenfalls am 9. Mai mit derselben Menge derselben Perlsuchtkultur infiziert. Es erkrankte am 17. Tage mit Fieber, zu dem einige Zeit später sehr starker Durchfall und (14. Juni) eitrig-schleimiger Ausfluß $B$ aus beiden Nasenlöchern hinzutrat, sodaß das Rind als maul- und klauenseucheverdächtig isoliert wurde. Es hatte übrigens in dieser Woche von $420 \mathrm{~kg}$ bis $390 \mathrm{~kg}$ abgenommen.

Mit dem Nasenauswurf wurde ein Meerschweinchen geimpft: dasselbe wies, zehn Wochen später getötet, Tuberculose der Leber, Milz, Lungen, Verkäsung der axillaren, bronchialen, prästernalen, mediastinalen, mesenterialen und inguinalen Drüsen auf. Auch in der Folgezeit war das Rind ofter kurzatmig und hustete. Als es am 12. August Tuberculin bekam, machte es schon wenige Stunden nach der Einspritzung einen schwer kranken Eindruck, fraß nicht, lag matt da, keuchte kurzatmig und hatte wiederum reichlichen Ausfluß aus der Nase. Ein weiterer erheblicher Unterschied zum vorbehandelten Rind bestand darin, daß bei diesem Kontrollrind die Tuberculinreaktion drei Tage hindurch anhielt. Am 17. August wurde es zusammen mit Rind V geschlachtet. In den Lungen fanden sich bei genauem Hinsehen unzählige feinste, dem Verlauf der Gefäße folgende Knötchen (Miliartuberkel). Die Bronchialdrüsen und Trachealdrüsen waren sämtlich mit älteren käsigen und jüngeren grauen Tuberkelknötchen durchsetzt,

1) Diese Knötchen sind auf rein mechanischem Wege dureh Capillarverstopfung Fremdkörperwirkung) der Schkr.-T.-B. entstanden und waren nicht imstande, Meerschwein u infizieren. Wir haben sie nur bei solchen Tieren beobachtet, die in der ersten Zeit, als unsere Schkr.-T.-B.-Emulsionen an Feinheit und GieichmäBigkeit noch zu wünschen übrig ließen, mit denselben intravenös behandelt worden waren. 
ebenso die Bugdrüsen. Nirgends Spuren von Bindegewebsentwicklung oder Abkapselung, überall der Prozeß im Fortschreiten begriffen. Die ganze Leber ist durchsetzt von unzähligen kleinen, mit bloßem Auge eben noch wahrnehmbaren, gelbgrauen Knötchen. Herr Geh.-Rat Orth, der die Güte hatte, mehrere mikroskopische Präparate zu begutachten, erklärte, daß diese Gebilde auch histologisch durchaus den Eindruck von Tuberkeln machen; in einem zerquetschten Knötchen wurden Perlsuchtbacillen nachgewiesen. Sowohl die mit Lunge als auch die mit Leber dieses Kantrollrindes geimpften Meerschweine erkrankten an allgemeiner Tuberculose.

Rind VI war mehrmals mit Schkr.-T.-B. intravenös vorbehandelt worden. Es hatte diese immunisierenden Injektionen in typischer Weise mit einem fast unmittelbar darauf einsetzenden und wenige (zwei bis vier) Tage anhaltenden Reaktionsfieber beantwortet, war dann wieder zur Normaltemperatur $\left(38,5-39,0^{\circ}\right)$ zurückgekehrt und dauernd normal geblieben. Es erhielt am 9. August die doppelte Menge derselben Perlsuchtkultur, mit der die oben beschriebenen beiden Rinder infiziert worden waren, intravenös, zeigte hierauf dieselbe sofortige Fieberreaktion, wie nach Schkr.-T.-B., die nach wenigen Tagen zur Norm zurückging. Im Gegensatz zu dem Kontrollrind VIII erfolgte nun aber am 17. Tage (dem bei intravenöser Perlsuchtinfektion für Rinder fast typischen Erkrankungstermin) kein weiterer Fieberanstieg, vielmehr dauernd normale Temperatur. Am 7. September wurde das Rind zum zweiten Male mit der dreimal so großen Menge Perlsuchtkultur wie das erste Mal infiziert, abermals akute Reaktion, nach drei Tagen abgeklungen, dann dauernd normale Temperatur. Das Rind nahm und nimmt während der Behandlung dauernd an Gewicht zu, es ist vor kurzem, am 15. Oktober, mit der zehnfachen Menge derselben Perlsuchtkultur intravenös infiziert worden und zeigte dasselbe typische Verhalten. Da es zu anderen Zwecken verwandt werden soll, wird es nicht getötet werden.

Jedenfalls beweisen diese Versuche, daß mit Schkr.-T.-B. in richtiger Weise vorbehandelte Rinder wiederholte Infektionen mit steigender erheblicher Menge hoch virulenter Perlsuchtkultur glatt zu vertragen imstande sind. Es sind zurzeit einige ganz analog geführte Rinderversuche in den Höchster Farbwerken im Gange.

$\mathrm{Zu}$ therapeutischen Zwecken bei bereits erkrankten Menschen oder Tieren sind bisher meines Wissens lebende Tuberkelbacillen noch nicht verwandt worden. Bei der vollständigen Nichtinfektiosität sowie vor allem der äußerst geringen Toxizität der Schkr. T.-B. schien ein derartiger Versuch beim perlsüchtigen Rind gerechtfertigt:

Rind III war am 20. November 1903 als zweifellos tuberculös eingestellt worden; es hatte auf $0,5 \mathrm{ccm} \mathrm{K}_{0} \mathrm{ch}$ sches Tuberculin von $38,5-41^{\circ}$ reagiert. Es wurde im Verlaufe der nächsten Monate zweimal mit intravenösen Injektionen meiner Kultur behandelt, die es glatt und unter ständiger Gewichtszunahme vertrug. Die letzte und höchste dieser Injektionen, die am 24. Februar 1904 erfolgte, hatte ein längere Zeit anhaltendes mit vorübergehender nicht unerheblicher Gewichtsabnahme verbundenes Fieber zur Folge. Als es sich vollkommen erholt hatte, die Temperatur wieder dauernd normal geworden und das alte Körpergewicht wieder erreicht war, wurde das Rind abermals mit Kochschem Tuberculin, und zwar diesmal mit der vierfachen Menge wie das erste Mal (2,0 ccm) geprüft (19. April). Es zeigte keine Spur einer Reaktion mehr und war auch nach Körpergewicht und Temperaturverlauf als geheilt $\mathrm{zu}$ betrachten. In der Folgezeit nahm das Rind an Gewicht ständig und erheblich zu, zeigte normale Temperatur und bestes Wohlbefinden. So wurde es am 13. Juni geschlachtet. Sektionsbefund: Eine Trachealdrüse enthält im Innern zahlreiche, gegen die Umgebung scharf abgesetzte gelbliche Herde; eine nächstliegende kleine Drüse enthält zwei ebensolche Herdchen. Bemerkenswert ist, daß die Herde in beiden Drüsen einen alten, vollkommen verheilten Eindruck machen: sie sind gröBtenteils verkalkt oder in Verkalkung begriffen. Beide Drüsen sind von derbem, mehrschichtigem Bindegewebe umgeben und vollständig abgekapselt. Alle sonstigen Körperdrüsen des Rindes und alle inneren Organe sind vollkommen freigeblieben und zeigen keine Spur tuberculöser Erkrankung.

Wir verfügen über Versuchsserien an Meerschweinen, die es als fast sicher erscheinen lassen, daß die bei diesem Rinde durch den vollkommenen Verlust der Tuberculinüberempfindlichkeit wie durch den Sektionsbefund bewiesene Heilung nicht spontan erfolgt, sondern durch die wiederholten Schkr.-T.-B.-Injektionen hervorgerufen worden ist. Es wird zurzeit ein ebenfalls spontan perlsüchtiges Rind in ähnlicher Weise systematisch mit Schkr.T.-B. zu heilen versucht.

Daßi die Schkr.-T.-B. für junge und alte Rinder vollkommen unsehädlich sind und bei technisch richtiger Applikationsmethode glatt aufgelöst werden, geht aus dem oben Ausgeführten hervor. Ebenso gelingt es bei richtiger Art der Verwendung bereits durch eine einmalige Injektion eine sehr hochgradige Grundimmunität zu schaffen, In diesen beiden Momenten liegen die grofen praktischen Vorzüge meiner Schkr.-T.-B. vor allen anderen Tubercul osekulturen. Insbesondere hinterlassen menschliche Tuberkelbacillen, wenigstens in der Mehrzahl der Fälle, im Rinderorganismus noch nach sehr langer Zeit spezifische Krankheitsherde mit virulenten Erregern (v. Behring, R. Koch, Orth, Thomassen, Mac Fadyean, Kossel u. a.). Vor allem geh aus dem großen Kosselschen Untersuchungsmaterial hervor, daß virulente Tuberkelbacillen selbst bei mit solchen menschlichen Stämmen behandelten Rindern noch nach mehreren Monaten fast ausnahmslos nachweisbar waren, die als "nicht-rinderpathogen" aufzufassen waren, d. h. keine disseminierte Tuberculose hervorriefen.

Es war nach dem oben Ausgeführten die Hoffnung vorhanden, daß auch in das Blut solcher mit Schkr.-T.-B. behandelter Säugetiere spezifische Schutzstoffe übergehen würden. Denn nach allen unseren Erfahrungen über natürliche und künstliche Immunität mub vor allen Dingen der aktiv immunisierte Organismus selbst das belebte oder unbelebte Gift glatt und spurlos verarbeitet haben, ehe man erwarten kann, daß Schutzkörper in sein Blut in solcher Menge abgestoßen werden, daß mit diesem auch bei anderen Tieren passiv Immunität, respektive Heilung zu erreichen ist. In der Tat habe ich die Existenz solcher Schutzstoffe im Blute mit Schkr.-T.-B. immunisierter Säugetiere durch meine in diesem Sommer in der Serumabteilung der Höchster Farbwerke ausgeführten Arbeiten nachweisen können, und zwar sowohl im Meerschweinserum als auch im Schweineserum und im Rinderserum.

\section{A. Meerschweinserum.}

1. Meerschwein.

Vorbehandelt mit dem Gesamtserum eines mit steigenden Mengen Schkr.-T.-B. immunisierten, dann entbluteten Meerschweins 10. Februar 1904 infiziert mit 0,002 g Perlsucht intraperitoneal. Gewichtszunahme von 605 bis $660 \mathrm{~g}$. Während der ganzen Zeit fieberfrei. 19. März getötet: bis auf vereinzelte ausschälbare Knötchen in der sehr kleinen Milz frei von T'uberculose.

Kontrollmeerschwein: 10. Februar 0,002 g Perlsucht intraperitoneal. Unter Fieber und Gewichtsabnahme nach drei Wochen tot. Kolossaler tuberculöser Netztumor mit Massen käsiger Knötchen; Käseknoten auf dem Peritoneum; Milz sehr stark geschwollen; Leber und Milz mit käsig fibrinösen Beschlägen. Mäßiges Peritonealexsudat.

\section{Meerschwein $230 \mathrm{~g}$.}

21. Juni. In die Bauchhöhle gespritzt mit dem Gesamtserum eines dreimal vorbehandelten Meerschweins.

22. Juni. Infiziert mit gehäufter Platinöse frischer menschlicher Tuberculosekultur.

12. August. Tot. Gewicht $400 \mathrm{~g}$. Todesursache: Lungenseuche. Sektionsergebnis: beide Leistendrüsen von harter Kapsel umgeben, enthalten im Zentrum käsige Herdchen. Alle inneren Organe, Lungen, Leber, Milz, ohne Spur von Tuberculose. Stelle des ehemaligen Impfgeschwürs nicht auffindbar.

Dieses Meerschwein erwies sich $51 \mathrm{Tage} n a c h$ der Infektion ohne Tuberculose der inneren Organe.

Kontrollmeerschwein: nach vier Wochen getötet; hochgradige allgemeine Tuberculose.

3. Meerschwein $190 \mathrm{~g}$.

30. Mai. Vorbehandelt mit Gesamtserum eines dreimal steigend immunisierten Meerschweins.

4. Juni. Mit Platinöse frischer menschlicher Kultur infiziert.

25. Juni 1904. Getötet; Gewicht $250 \mathrm{~g}$. Impfstelle verheilt. Sektion (in Gegenwart von S. R. Libbertz und Prof. Ruppel). Beide Leistendrüsen mäßig geschwollen; im Innern käsige Herdchen. Innere Organe frei. Das Meerschwein war während der ganzen Zeit fieberfrei.

Kontrollmeerschwein: 255 g. Gleichzeitig infiziert, gleichzeitig getötet. Bei der Tötung Gewicht $180 \mathrm{~g}$. Impfgeschwür besteht; Sektionsergebnis : beide Leistendrüsenpaare erheblich geschwollen, enthalten im Zentrum und am Rande verkäste Herde. In der Leber mäßig zahlreiche weißgelbe Knötchen, Milz um das Vierfache vergrößert, tuberculös. In den Lungen bereits zahlreiche kleine Knötchen. Das Meerschwein hatte vom zweiten Tage nach der Infektion an bis zum Tode ein zwischen $39,8^{\circ}$ und $40,5^{\circ}$ schwankendes Fieber gehabt.

4. Meerschwein $245 \mathrm{~g}$.

8. Juni 1904. Vorbehandelt mit Gesamtserum eines viermal immunisierten Meerschweins.

10. Juni 1904. Infiziert mit Platinöse frischer menschlicher Kultur.

12. Juni 1904. Nochmals mit gleichem Serum behandelt.

2. Juli 1904. Impfstelle glatt.

4. Juli 1904. Tot. Sektion (in Gegenwart von S. R. Libbertz); rechte Leistendrüse etwas geschwollen. Im Innern eine kleine Höhle mit erweichtem Inhalt; linke Leistendrüse nicht geschwollen. Milz, Leber und Lungen vollkommen gesund. 
Kontrollmeerschwein: Impfgeschwür. Allgemeine Tuberculose. B. Rinderserum.

1. Meerschwein $265 \mathrm{~g}$. Dreimal vorbehandelt mit Rinderserum (Rind 1).

14. Juni 1904. Infiziert mit Platinöse frischer menschlicher Kultur. Vom 22. Juni $1904 \mathrm{ab}$ alle zwei bis drei Tage Serum.

7. Juli 1904. Getötet. Gewicht $355 \mathrm{~g}$. Sektion in Gegenwart von S. R. Libbertz; die gleichseitige Leistendrüse ist im Innern verkäst, die gegenseitige gesund, auch nicht vergrößert. Alle inneren Organe; Lungen, Leber, Milz, vollkommen normal.

2. Meerschwein 260 g. Ebenso behandelt.

13. Juni 1904. Infiziert mit Platinöse frischer menschlicher Kultur. 15. Juli 1904. Getötet. Gleichseitige Leistendrüse im Innern etwas verkäst. Gegenseitige ganz normal. Alle inneren Organe, Lungen, Leber, Milz, vollkommen gesund.

3. Meerschwein 585 g. Ebenso behandelt (mit Serum Rind VII).

16. Juli 1904. Infiziert von Herrn S. R. Libbertz mit gehäufter Platinöse zwölftägiger menschlicher Agarkultur.

15. August 1904. Tot. Todesursache Peritonitis. Sektionsergebnis (mit S. R. Libbertz festgestellt): beide Leistendrüsen enthalten kleinste käsige Herdchen. Kein Impfgeschwïr. Impfstelle glatt. Innere Organe, Lungen, Leber, Milz, frei von Tuberculose.

4. Meerschwein $440 \mathrm{~g}$. Ebenso behandelt.

16. Juli 1904. Infiziert mit gehäufter Platinöse 16 tägiger menschlicher Kultur.

16. August 1904. Tot. Todesursache Pneumonie. Sektionsergebnis (zusammen mit S. R. Libbertz und Prof. Rup pel festgestellt): Gleichseitige Leistendrüse verkäst. Alle inneren Organe, Lungen, Leber, Milz, ohne jede Spur von Tuberculose.

Sämtliche Kontrollmeerschweine zu den letzterwähnten Tieren, und zwar sowohl die nur infizierten als auch die mit entsprechenden Serummengen eines nicht immunisierten Rindes behandelten zeigten innerhalb des gleichen Zeitsraums Tuberculose meist aller inneren Organe, jedenfalls der Leber und Milz.

Die folgenden Meerschweine wurden ebenfalls alle zwei bis drei Tage vor und nach der - von Herrn Prof. Ruppel vorgenommenen Infektion mit Blutbestandteilen (insbesondere Serum) von Rind I behandelt.

5. Meerschwein

7. September. Mit $1 \mathrm{mg} \mathrm{z}$ wölftägiger Kultur infiziert.

29. September. Tot; häutchenartige Auflagerungen auf Leber und Milz. Alle Organe frei von Tuberculose.

6. Meerschwein.

10. September. Infiziert mit $1 \mathrm{mg}$.

30. September. Tot. Vollkommen frei von Tuberculose.

7. Meerschwein.

7. September. Infiziert mit $0,5 \mathrm{mg}$.

29. September. Getötet. Innere Organe frei von Tuberculose.

8. Meerschwein.

7. September. $0,5 \mathrm{mg}$ infiziert.

29. September. Getötet. Innere Organe frei von Tuberculose.

Folgende fünf Kontrollmeerschweine wurden gleichzeitig von Herrn Prof. Ruppel infiziert.

a) 7. September. 0,5 mg menschliche Kultur.

29. September. Getötet. Hochgradige Tuberculose der Leber und

Milz. Tuberculöser Netztumor, $25 \mathrm{ccm}$ blutiges Peritonealexsudat.

b) 7. September. $1 \mathrm{mg}$ menschliche Kultur.

29. September. Getötet. Leber und Milz von unzähligen Knötchen auf Oberfläche und Schnittfläche durchsetzt.

c) 7. September. $1 \mathrm{mg}$ menschliche Kultur.

29. September. Getötet. Leber mit unzähligen Knötchen übersät;

Milz dunkelrot geschwollen mit vielen Knötchen.

d) 7. September. $0,5 \mathrm{mg}$ menschliche Kultur.

29. September. Getötet. Tuberculöser Netztumor. Milz geschwollen, mit Knötchen durchsetzt. Lebertuberculose mäßig vorgeschritten.

e) 10. September. $0,5 \mathrm{mg}$ menschliche Kultur.

30. September. Getötet. Ziemlich hochgradige Tuberculose der Leber und Milz. Beide Organe auf der Oberfläche und allen Schnittflächen von Knötchen durchsetzt.

9. Meerschwein (No. 104). Von Herrn Prof. Ruppel mit Serum Rind I behandelt, infiziert und seziert.

7. September. $1 \mathrm{mg}$ menschliche Kultur.

30. September. Getötet. Sectionsprotokoll: Sehr unwesentlich vergrößerte Leistendrüsen ohne Verkäsung. Die Leber ist vollkommen glatt und frei ron Knötchen. Die Milz ist sehr wenig vergrößert, von normaler Farbe und ohne Knötchen, Lungen frei.

Kontrollmeerschwein zu diesem Versuch (No.39) gleichzeitig infiziert und gleïhzeitig getötet. Sektionsprotokoll: Nur wenig vergrößerte, nicht verkäste Drüsen. Reichliches, seröses Exsudat in der Bauchhöhle. Leber mit zahllosen Knötchen von verschiedener Größe bedeckt. Die Milz ist nicht vergrößert, jedoch mit der Bauchwand und dem Darm verlötet und enthält zahlreiche Knötchen. Auch in den Lungen finden sich vereinzelte graue Knötchen.
Hervorgehoben sei noch, daß sämtliche Versuchstiere sowohl die subcutane als die intraperitioneale Einverleibung sehr erheblicher Serummengen glatt und spurlos überstanden haben.

1. Meerschwein.

$$
\text { C. Schweineserum. }
$$

30. August. $1 \mathrm{mg}$ frische menschliche Kultur verrieben in $2 \mathrm{ccm}$ Serum. Keine weitere Serumbehandlung.

16. Oktober Getötet. Regionäre Leistendrüse verkäst. Innere Organe frei von Tuberculose.

2. Meerschwein. Zweimalige Vorbehandlung mit Serum.

30. August. $1 \mathrm{mg}$ frische, menschliche Kultur verrieben in $2 \mathrm{ccm}$ Serum. Dann alle zwei bis drei Tage bis zum 21. September Serumbehandlung.

10. Oktober. Tot. Linke Leistendrüse verkäst, sonst vollkommen frei von Tuberculose.

3. Meerschwein. Ebenso wie 2 behandelt, gleichzeitig infiziert und getötet. Bis auf regionäre Drüsenverkäsung frei von Tuberculose.

Kontrollmeerschweine allgemeine Tuberculose.

Es ist also hier zum ersten Male gelungen, bei dem empfänglichsten Tuberculoseversuchstier gegen eine virulente Infektion durch Serumbehandlung einen nicht unerheblichen Schutz zu erzielen. Mit Recht betont nun Maragliano den „groben Unterschied $z$ wischen der natürlichen Infektion des Menschen und der experimentellen des Meerschweinchens, da wir im ersten Fall gegen keine so grobe Menge von auf einmal eingedrungenen virulenten Bacillen $z$ kämpfen haben, wie es der Fall ist, wenn ein Meerschweinchen experimentell infiziert wird", und ferner, "dah normalerweise bei dem Menschen die Infektion nicht so stürmisch stattfindet wie bei der experimentellen Tuberculose der Tiere". Dak wir bei Verwendung von Meerschweinserum bei Meerschweinen mit einer oder wenigen Injektionen ausgekommen sind, während bei Verwendung von Rinderserum offenbar viel häufigere Injektionen zweckmäßig waren, ist leicht verständlich. Denn Meerschweinserum ist für Meerschweine homologes Serum, während Rinderserum, für den Meerschweinkörper ein heterologes, fremdartiges Serum, aus diesem viel eher ausgeschieden wird, also ersetzt werden muB. Natürlich muß es das Endziel tuberculosetherapeutischer Arbeiten sein, ein so hochwertiges Schutz- und Heilserum zu erlangen, daß schon eine geringe Menge desselben eine virulente Infektion mit Sicherheit unschädlich zu machen imstande ist. Zur Erreichung dieses Zweckes ist es nach dem oben Ausgeführten möglich, die durch Schkr.-T.-B. erreichte Grundimmunität durch Behandlung mit virulenten Kulturen hoch zu treiben. Solche Versuche sind zur Zeit in den Höchster Farbwerken im Gange.

In weiterer Verfolgung dieses Gedankens muß man schließen, daf das vom Rinde stammende Immunserum andere Rinder zu schützen vermag, und auch hier muß man durch steigende Behandlung mit virulenter Kultur zu immer höherwertigem Serum gelangen.

Endlich sei erwähnt, daß ich einen gröberen Bestand von Kälbern auf der Majoratsherrschaft des Herrn Reichsgrafen v. Oppersdorff mit meinem Impfstoff immunisiert habe und daf nach einem mir kürzlich zugegangenen Bericht sämtliche Kälber wohl sind. Ueber das Ergebnis dieser und weiterer Versuche hoffe ich in einiger Zeit berichten zu können. 